\title{
LA FÁBRICA DE LA FICCIÓN. VIDA, TRABAJO \\ Y ESCRITURA EN ERA EL CIELO Y EL ESCRITOR \\ COMIDO DE SERGIO BIZZIO*
}

\author{
Cecilia Sánchez Idiart \\ Universidad de Buenos Aires \\ cecisi89@gmail.com
}

Recibido: 26/03/2018 - Aceptado: 23/09/2018

doi.org/10.17533/udea.lyl.n75a03

\begin{abstract}
Resumen: A partir de la indagación de las imbricaciones contemporáneas entre la vida y el capital, las novelas Era el cielo (2007) y El escritor comido (2010), del argentino Sergio Bizzio, problematizan específicamente el trabajo del escritor y se preguntan, al mismo tiempo, por los límites de lo literario y las condiciones de su producción y circulación en el presente. Por medio de una ética del fracaso y del procedimiento del extrañamiento, estas ficciones imaginan también posibilidades de vida y de escritura que no se someten a los dictámenes del mercado y a su imperativo de éxito.
\end{abstract}

Palabras clave: trabajo; vida; escritura; literatura latinoamericana contemporánea; Sergio Bizzio.

\section{THE FACTORY OF FICTION. LIFE, WORK AND WRITING IN ERA EL CIELO AND EL ESCRITOR COMIDO BY SERGIO BIZZIO}

\begin{abstract}
Through the exploration of the contemporary imbrications between life and capital, the novels Era el cielo (2007) and El escritor comido (2010), by the Argentine Sergio Bizzio, problematize specifically the work of the writer and interrogate, at the same time, the limits of literature and the conditions of its production and circulation in the present. By means of an ethics of failure and of the procedure of estrangement, these fictions also imagine possibilities of life and writing that do not submit to the dictates of the market and its imperative to succeed.
\end{abstract}

Keywords: Work; Life; Writing; Contemporary Latin American Literature; Sergio Bizzio.

\footnotetext{
* Este artículo se inscribe en el proyecto de investigación doctoral "Reinventar lo común. Configuraciones de la vida, la política y los afectos en la literatura latinoamericana contemporánea" financiado por el Consejo Nacional de Investigaciones Científicas y Técnicas y con sede en el Instituto de Filología y Literaturas Hispánicas "Dr. Amado Alonso" de la Facultad de Filosofía y Letras de la Universidad de Buenos Aires.
} 


\section{La vida puesta a trabajar}

$\mathrm{E}$ n Gramática de la multitud, el filósofo italiano Paolo Virno (2008) se dedica a analizar las formas de trabajo contemporáneas y registra, tras la declinación del fordismo, la emergencia y consolidación de un modo de producción que, más allá del régimen de encierro de la fábrica, encuentra en el virtuosismo de la actividad del hablante la potencia de una nueva fuerza productiva. La actividad virtuosa involucra las capacidades de un artista ejecutante y, en este sentido, supone una performance que no se objetiva en una obra o un producto terminado y que requiere de la presencia de un público. En un proceso productivo dominado crecientemente por la circulación de la información, la comunicación y la cooperación social, el lenguaje, actividad virtuosa por excelencia, pasa a ocupar un lugar central: «La informalidad de la acción comunicativa, la interacción competitiva típica de una reunión, la brusca variación que puede animar un programa televisivo [...] hoy, en la época posfordista, se volvió un aspecto típico de toda producción social» (p. 56; las cursivas son del original).

Esta transformación pone en crisis la tradicional comprensión de la experiencia humana — propuesta por Aristóteles y retomada luego por Hannah Arendt (1993) en su distinción entre labor, trabajo y acción — a partir de las dimensiones del trabajo como proceso repetitivo y previsible de intercambio con la naturaleza y de producción de objetos nuevos, el intelecto como reflexión teórica solitaria y la acción política en tanto intervención pública en las relaciones sociales abierta a lo imprevisible y contingente. El trabajo posfordista, según Virno, se apropia de algunas de las características fundamentales de la praxis política (principalmente, la exposición ante un público y la improvisación derivada de la imprevisibilidad de lo social) y pone en juego las competencias lingüísticas y las capacidades intelectuales de la especie humana.

Por su parte, Gilles Deleuze (1996) ofrece un diagnóstico complementario al de Virno. Si las sociedades disciplinarias constituidas en el siglo XVIII y consolidadas a lo largo de los siglos XIX y XX se apoyaban en el régimen de encierro de instituciones como el hospital, la cárcel, la fábrica y la escuela, la sociedad de control contemporánea aspira a la regulación a cielo abierto de la circulación de personas y cosas - y en esto coincide con el funcionamiento de aquello que Michel Foucault (2006, p. 20) llama "dispositivo de seguridad"-, a la vez que a la modulación continua de la subjetividad a través de las tecnologías de la información. Así, mientras que la fábrica «hacía de los individuos un cuerpo» (Deleuze, 1996, p. 280), de manera tal que el conjunto de los trabajadores resultaba inteligible, tanto para el patrón como para los sindicatos, bajo el régimen homogéneo de la masa, la empresa en la sociedad de control, en cambio, instala entre los individuos 
una relación de feroz competencia que contrapone unos a otros, los atraviesa y los divide interiormente.

En el marco de la consolidación a escala global del capitalismo posfordista y de la implantación del neoliberalismo en América Latina a partir de las dictaduras de los años setenta, una serie de obras literarias contemporáneas producidas en la región se han consagrado a explorar las imbricaciones actuales entre la vida y el trabajo. Desde El aire (1992) y Boca de lobo (2000) de Sergio Chejfec o Mano de obra (2002) de Diamela Eltit hasta Fruta podrida (2007) de Lina Meruane o Ellos eran muchos caballos de Luiz Ruffato (2001), pasando por El desperdicio (2007) de Matilde Sánchez, Cuaderno de campo (2014) de Carlos Ríos y De ganados y de hombres (2013) de Ana Paula Maia, estas novelas indagan de modo diverso la inscripción del capital en la vida, las relaciones entre lo viviente y el mercado, y los modos de subjetivación que produce el trabajo. En particular, las novelas Era el cielo (2007) y El escritor comido (2010), del escritor, guionista, director de cine y músico argentino Sergio Bizzio, problematizan específicamente el trabajo del escritor y el proceso de la escritura, y se preguntan, al mismo tiempo, por los límites de lo literario y las condiciones contemporáneas de su producción y circulación. En la medida en que estas ficciones reformulan las articulaciones entre el trabajo de la escritura y la vida del escritor, y desdibujan las fronteras de lo que se reconoce como literario, resulta pertinente recuperar algunas discusiones actuales en torno a las condiciones y el estatuto de la literatura y las artes en el presente.

Desde hace ya algunas décadas, diversas investigaciones críticas comenzaron a teorizar sobre una visible tendencia hacia la inespecificidad de los soportes, los materiales, las categorías estéticas y los modos de producción, circulación y recepción puestos en juego por toda una serie de prácticas artísticas que se desarrollaron por lo menos a partir de los años sesenta. En los distintos campos de las artes - la pintura (Silverman, 2009), la fotografía (Krauss, 1999), la escultura (Krauss, 1979), el teatro (Féral, 2002), el cine (Oubiña, 2010), la literatura (Laddaga, 2007; Garramuño, 2009; Ludmer, 2010)_, numerosas exploraciones estéticas apuntaban precisamente a la desestabilización de las convenciones y criterios que gobernaban la delimitación de aquellos campos disciplinares y a la producción de otras formas de experiencia artística que desafiaran estas particiones a partir de la postulación de lo que Rosalind Krauss (1979) llamó, en su pionero ensayo, un «campo expandido».

En dos libros de aparición casi simultánea, Estética de la emergencia (2006) y Espectáculos de realidad (2007), Reinaldo Laddaga recorre una transformación radical en la cultura de las artes del presente. Si la estética de la modernidad desarrollada a partir de finales del siglo XVIII se organizaba alrededor de una noción de obra como objetivación de la práctica artística que era puesta en circulación a través 
de espacios institucionales clásicos y se dirigía a un espectador o lector solitario y silencioso, en las últimas décadas numerosos proyectos artísticos, antes que materializarse en objetos, comienzan a preocuparse por «diseñar experiencias» (Laddaga, 2007 , p. 9) y producir nuevas configuraciones de la vida común. Se trata de experimentaciones comunitarias que, en sintonía con la actividad virtuosa que Virno sitúa en el centro del modo de producción posfordista, cobran consistencia alrededor de lo que Laddaga entiende como un régimen práctico de las artes que ya no acepta lo disciplinario como modo de organización de la vida colectiva, sino que apuesta por la invención de modos de asociación que asumen como condiciones la variabilidad y la improvisación, y trazan nuevas conexiones entre la estética, la política y la vida.

Si bien Florencia Garramuño trabaja con materiales, cortes temporales y categorías teóricas diferentes, La experiencia opaca (2009) toma como punto de partida una constatación semejante y complementaria a la de Laddaga. La tesis fundamental del libro sostiene que durante los años setenta y ochenta las prácticas de escritura en las culturas argentina y brasileña comienzan a ensayar nuevas articulaciones entre el arte y la experiencia, sin suscribir ya a los presupuestos autonomistas del modernismo ni tampoco a las ilusiones utópicas y la exigencia de compromiso político de las segundas vanguardias. Acudiendo a formas de la errancia, la marginalidad y el trabajo con los restos, entre otros procedimientos, estas producciones desconfian de las promesas de la modernización para proponer otras vías de politización de la literatura y nuevas vinculaciones entre la estética y la vida. Por otro lado, en Mundos en común, su libro más reciente, Garramuño (2015) continúa esta línea de indagación a través del análisis de la producción de comunidades expandidas por parte de un conjunto de prácticas estéticas de las últimas décadas que, al desdibujar las fronteras tradicionales entre las artes, cuestionan los regímenes de propiedad y pertenencia de los que dependen la especificidad del sujeto, la nación y la lengua, y deconstruyen radicalmente «todo tipo de ideas de lo propio, tanto en el sentido de lo idéntico a sí mismo como en el de limpio o puro, pero también [...] como aquella característica que diferencia a una especie de la otra» (p. 157). Incluso en producciones que todavía pueden seguir siendo pensadas como literatura, se advierte una dinámica de creciente inespecificidad que afecta los géneros, las modalidades discursivas y las categorías estéticas a través de las cuales la cultura de la modernidad delimitó el campo literario y estableció particiones hacia su interior.

Era el cielo y El escritor comido intervienen en estos debates alrededor de las condiciones de la producción estética en el presente a través de la puesta en escena del trabajo del escritor y de la indagación, a partir de allí, de las imbricaciones entre el capital, el cuerpo y la vida. Lejos de cualquier ideal romántico de la escritura como creación libre, solitaria y autónoma de un sujeto concebido como genio inspirado, 
las novelas ponen en evidencia los vínculos entre la literatura y el mercado, ${ }^{1}$ a la vez que interrogan los modos en que la materia de la vida y lo viviente se inscribe en la producción estética y cultural contemporánea. La literatura dista de perfilarse en estas narraciones como campo autónomo y autorreferencial, y se exhibe, en cambio, en sus contaminaciones con otros intereses, experiencias y discursos.

Por un lado, Era el cielo confronta diversas prácticas de escritura diferenciadas de acuerdo con su grado de éxito en el mercado, y explora la capitalización de la experiencia vivida como paso ineludible en el proceso de profesionalización del escritor y de la construcción de una figura pública. Por otro lado, El escritor comido radicaliza esta premisa al narrar la mercantilización de la experiencia de desfiguración y extremo despojamiento atravesada por el escritor de best-sellers Mauro Saupol. En la exploración de los modos en que la escritura, más allá de cualquier pretensión de autonomía, puede convertirse en un trabajo que pone en juego dimensiones cada vez más amplias de la vida social, ambas novelas se preguntan por el estatuto y los límites de lo literario en un presente definido por la permeabilidad de los soportes y las disciplinas estéticas, a la vez que problematizan la captura de lo viviente por parte de los dispositivos neoliberales de gobierno que aprehenden la vida como capital humano. A través de una ética del fracaso y del procedimiento del extrañamiento, estas ficciones imaginan también posibilidades de vida y de escritura que se desvían de los dictámenes del mercado y de su imperativo de éxito.

\section{Cómo vivir de la escritura y (no) naufragar en el intento}

Era el cielo narra en primera persona la historia de un guionista de televisión que un día, al llegar a su casa, descubre a dos hombres violando a su mujer. Tras el intenso desacomodamiento que produce esta escena inicial, la novela se sumerge en el pasado del narrador para encadenar una serie de episodios de su vida laboral y amorosa, y se focaliza especialmente en su relación tensionada con la escritura. Al proponer una clasificación del público asistente a la fiesta de cumpleaños de un cirujano plástico, el narrador ofrece una extensa e irónica descripción del trabajo y el modo de vida del guionista:

El guionista de una tira diaria es un ser relativamente vivo que se desloma mecanografiando para el aire. Si no fuera porque suele forrarse, el carácter intrascendente de su esfuerzo lo haría rabiar en la misma medida en que la desesperación por lo masivo atrofia

1 En un ensayo en torno a los escritores argentinos de la década de los noventa, Edgardo Berg (1996) inscribe la literatura de Sergio Bizzio en el marco de un interés compartido por la problematización de las relaciones entre el valor literario y el valor mercantil, así como por el cruce de "formas provenientes de la cultura popular o de masas con problemáticas propias de la alta cultura o de la vanguardia histórica" (p. 37). 
su sentido del humor, si es que lo tenía antes de lanzarse a la aventura; el éxito - la composición de la fórmula del éxito, cada vez más conocida y mejor articulada por un puñado de empresas creadoras de la tribu millonaria de adoradores de Lo Mismo- es su única satisfacción aparte del dinero, aunque no se le atribuya a él más que en una muy pequeña dosis (una dosis de palmaditas en la espalda durante un encuentro casual en un pasillo), por lo cual se resiente y, paradójicamente, empieza a creer en lo que hace: fue $s u$ calidad la que produjo esa cantidad — de espectadores, de segundos publicitarios. Así que ni humor ni rabia y mucha fe (Bizzio, 2011, pp. 42-43; las cursivas son del original).

Así, los guionistas consumen su vida comprometiéndose con una práctica de escritura puesta al servicio de una fórmula empresarial del éxito que entiende la calidad en términos de cantidad, de beneficio económico. La televisión se configura a lo largo de la novela como una industria consagrada a la «dosificación de la nada» (p. 93), a un culto de Lo Mismo agitado, en caso de que el descenso del rating lo requiera, por golpes bajos y emociones fuertes que puedan volver a atraer la atención de los espectadores. Si «la producción de subjetividad, de formas de vida, de modalidades de existencia» (Lazzarato, 2013, p. 41) ocupa un lugar central en la producción económica contemporánea, la figura del guionista se construye en la novela de Bizzio precisamente como un modo de vida sometido a las exigencias del mercado, como un sujeto signado por una fe casi religiosa y una falta de sentido del humor que le impiden advertir la intrascendencia de su trabajo.

Al inicio de la segunda parte de la novela, el narrador conoce a Vera en la fiesta de fin de año del canal de televisión donde ambos trabajan como guionistas. El salón estaba repleto de agentes, productores, actores, ejecutivos, periodistas y guionistas, «todos cómicamente vestidos según su rol [...] en un clima heterogéneo de triunfo, promesa y ansiedad, regado por un champagne que, sin ser malo, dejaba entrever que respondía a un presupuesto» (Bizzio, 2011, p. 33). Aquí, nuevamente, la narración subraya que la industria de la televisión produce subjetividades marcadas por un deseo de pertenencia y por la racionalización económica de los recursos, por las conductas repetitivas y automatizadas que develan «la despreocupación rutinaria de un editor mal pago» (p. 34), y por una gestión de los afectos que impone una confianza imperturbable en un futuro previsible. El trabajo del guionista en tanto dispositivo de subjetivación reduce, de esta manera, la vida a la adecuación de una fórmula, a la cifra de un éxito cuantificado, y a la llanura de una estetización homogeneizadora de los cuerpos y de una temporalidad clausurada y controlable.

En la configuración de un campo de tensiones entre diferentes prácticas de escritura, más o menos exitosas en términos de mercado, Era el cielo también presenta y pone en discusión la figura de un escritor profesionalizado. Si en el cuento «Cinismo», incluido en Chicos, Bizzio definía al genio como «aquél capaz de convertirse 
en una industria de producir historia personal, y en algunos casos obra» (2012, p. 9; las cursivas son del original), en Era el cielo, a través del personaje de Horacio Tambutti, el único escritor profesional amigo de Vera, el narrador exhibe una plena conciencia de que convertirse en un escritor de éxito supone la producción de una imagen pública y de una historia de vida. Como se volverá todavía más evidente en El escritor comido, la profesionalización del escritor en el siglo XxI exige una disposición a capitalizar algún episodio de la propia vida para convertirlo en best-seller: Tambutti pasa siete años en coma luego de que una mujer anónima le dispara un tiro en la cabeza y, una vez que se recupera, escribe un libro sobre esa experiencia que se convierte en «un gran éxito de ventas, un éxito notable, inmenso, descomunal» (Bizzio, 2011, p. 112). El narrador, tras comenzar a escuchar la respuesta del escritor, «pulida como un texto» (p. 113) y ensayada incontables veces, a la pregunta del «¿cómo fue?» — también incesantemente repetida porque la celebridad del autor «se basaba en un hecho real» (p. 112)_-, se convence de que la fama de Tambutti depende exclusivamente de un golpe de suerte y de la fabricación de una narración «fácil de entender» (p. 113) que permite capitalizar y convertir en mercancía una experiencia límite. En el contexto de una industria cultural donde todo es «sordo, enroscado, servil, automático, negociable y lateral» (p. 34), aquel que pretenda vivir de la escritura tiene que ser capaz de encontrar o producir el golpe de efecto que lo catapulte a la fama, $\mathrm{y}$, además, de poner en práctica una performance que cautive al público. Siguiendo a Foucault (2008) en su lectura del neoliberalismo, la vida del escritor profesional se convierte en Era el cielo en una verdadera fábrica de capital humano: ${ }^{2}$ en tanto empresario de sí mismo, el escritor es garante y custodio de su propia productividad y es responsable de su valorización en el mercado.

El escritor comido parece retomar, transfigurar y llevar al extremo las posibilidades narrativas abiertas por el personaje de Tambutti. En efecto, la novela comienza con un planteo radical: un escritor brasileño de best-sellers, Mauro Saupol, decide hacerse pasar por muerto luego de un accidente de avión «para ver qué se decía de él», ya que «todo lo demás ya lo tenía» (Bizzio, 2010, p. 7). Cuando el escritor ha adoptado y perfeccionado al máximo la fórmula del éxito, la única alternativa posible parece ser la de desaparecer. A lo largo de las cinco partes que componen la novela, muy heterogéneas entre sí, Saupol es devorado por los habitantes de una aldea exótica, luego es rescatado y regresa a la civilización, se realiza trasplantes y cirugías estéticas para recomponer su rostro y su cuerpo, y, finalmente, tras darse

2 En El nacimiento de la biopolítica, a partir de la teoría del capital humano desarrollada por la Escuela de Chicago, Foucault aspira a comprender el neoliberalismo no meramente como una doctrina económica, sino como un modo de gobierno de la vida que despliega una racionalidad de mercado sobre todo el campo de lo social. El capital humano remite a la figura de un sujeto aprehendido como homo oeconomicus o empresario de sí mismo que es responsable de su propia productividad, mejora y valorización en cuanto capital. 
cuenta de que un periodista es capaz de narrar mejor que él mismo su propia vida, viaja a Venecia para alejarse, una vez más, de todo.

Saupol es presentado por el narrador en tercera persona como un «hit viviente»: «sus libros, una serie de cinco ficciones de corte espiritual [...] eran los más exitosos de la industria editorial de la última década [...]. Cualquier cosa que entregaba a la industria vendía millones, y a tal velocidad que ya ni siquiera él se preguntaba por qué» (p. 11). El modo de producción de Saupol se describe a partir de un trabajo con la propia vida y con máximas morales que da como resultado una narración con pretensiones pedagógicas y universalizantes:

Tomaba un aforismo, o una máxima, o una anécdota, preferentemente de algún libro tibetano (o zen, o sufi, o pop) y, aplicándola a algún episodio de su propia vida, la desplegaba hasta convertirla en una historia, o en algo parecido a una historia, con personajes moralmente muy bien delineados —él era siempre el personaje principal—y un comienzo y un desarrollo que se empujaban uno a otro en una carrera de rutina hacia la moraleja del final. Y siempre, siempre, siempre funcionaba (p. 12).

En El escritor comido, es la industria editorial y no ya la televisiva la que impone a la escritura la fórmula de Lo Mismo como garantía de éxito en el mercado. Saupol publica libros cargados de «verdades y emoción» (p. 86), cuyas lecciones morales, abstractas y mistificadoras, son dignas de un libro de autoayuda: «todos los hombres son extraordinarios» (p. 87); «todos venimos del mismo rayo y somos parte de su misma luz» (p. 89). Las fábulas moralizantes y tranquilizadoras son las que llevan al mayor éxito de ventas, y más aún si el autor está dispuesto a convertir en mercancía su propia vida y su cuerpo, e incluso a que su nombre sea reconocido como una marca. Como señala Alejandra Laera en su lectura de un conjunto de ficciones del trabajo argentinas, aquí también se pone en escena «el desafío de la escritura como trabajo con la experiencia» (2016, p. 165), al mismo tiempo que se exhibe como espectáculo el trabajo del escritor. Ya desde las páginas iniciales se vuelve evidente que la vida de Saupol se convierte en una «industria de producción de historia personal» (Bizzio, 2012, p. 9) cuando su mujer Ingrid le sugiere la idea - de gran atractivo para el mercado por lo que supone de escandalosa - de publicar una biografía que confesara su «pasado de dealer y de alcohólico, además de dos relaciones homosexuales» (Bizzio, 2010, p. 12).

Pero tal vez la apuesta más radical de El escritor comido reside en que la mercantilización de lo viviente penetra hasta el núcleo duro de la vida biológica, ya que, hacia el final de la novela, aquello que se comercializa es la narración de la experiencia de extrema desubjetivación y desfiguración vivida por Saupol en la selva: «la foto que había hecho gemir a Pavel era la última del libro: un hombre sin cara, un hombre 
terriblemente lastimado, Mauro Saupol» (p. 199; las cursivas son del original). Los lectores compran y leen con avidez la biografía de un hombre en la que el golpe de efecto más bajo (y, por tanto, más eficaz) consiste en su reducción a nuda vida, ${ }^{3} \mathrm{a}$ un cuerpo canibalizado y desfigurado más allá de todo reconocimiento.

\section{Más allá del mercado: entre el fracaso y el extrañamiento}

Una de las preocupaciones centrales en Era el cielo y El escritor comido es la pregunta por las formas de trabajo del escritor y los modos de subjetivación producidos por las industrias televisiva y editorial entendidas como dispositivos que instrumentalizan la vida para convertirla en tiempo productivo, en best-seller, en camino lineal hacia una promesa de éxito. Ante las técnicas de racionalización e industrialización de lo viviente por medio de las cuales instituyen su gobierno las formas de trabajo de la industria cultural, ${ }^{4}$ las novelas de Bizzio modelan configuraciones de la vida que componen estéticas de la existencia alternativas a las que exige el mercado. Ambas ficciones desarreglan el modelo de una escritura exitosa en términos de cantidad de ventas para delinear posibilidades de vida que escapan al gobierno del capital sobre lo viviente. En este sentido, Era el cielo y El escritor comido otorgan gran importancia a aquello que Roland Barthes (2005) en La preparación de la novela denominaba «tangibilia» y que entendía como la captación de incidentes imperceptibles ajenos al estereotipo, a la doxa. Es sobre todo a través de una estética del extrañamiento que estas ficciones piensan la vida común y reconfiguran los modos de percepción y las relaciones afectivas entre los cuerpos para desarreglar el paradigma de una vida sometida al trabajo.

En el caso de Era el cielo, es a través del humor cínico y de una ética del fracaso vinculada a una temporalidad improductiva que el narrador busca una y otra vez desmarcarse de la forma de vida impuesta por su trabajo como guionista televisivo para ensayar otros modos posibles de narrar una vida, ya no atravesados por el deseo de pertenecer e identificarse sin fisuras con un determinado grupo social. Al encontrarse con Trini, el guionista novio del cirujano que festejaba el cumpleaños, el narrador expresa un desprecio hacia este personaje que le permite reconocer una proximidad a la vez que trazar una distancia: «Yo no era mejor persona que él, pero

3 Vale la pena precisar que, en la filosofía de Giorgio Agamben (2004), la noción de nuda vida no remite a un dato natural sino al resultado de una producción del poder que aísla en el campo de lo viviente un sustrato biológico como zona de intervención.

4 Para Virno (2008), en el posfordismo, la comunicación humana se convierte en la principal fuerza productiva y, por lo tanto, la industria cultural pasa a ser la industria de los medios de producción, ya que es ella la que crea, innova y experimenta con técnicas y procesos comunicativos que desarrollan los instrumentos de producción del trabajo posfordista. 
al menos podía reírme» (Bizzio, 2011, p. 43). El humor funciona en la novela como mecanismo que opera un desplazamiento respecto de la religión de Lo Mismo dominante en el mundo de la televisión, a la vez que habilita la invención de nuevas posibilidades para un lenguaje aprisionado en las lógicas acartonadas del éxito y la cuantificación.

En su estudio sobre los cínicos, Michel Onfray (2009) refiere a la espontaneidad lúdica, el humorismo y los juegos de palabras mediante los cuales estos filósofos desbarataban el espíritu de gravedad característico del discurso filosófico para descubrir en el lenguaje nuevas posibilidades ya no regidas por una racionalidad meramente comunicativa. Por medio del recurso al humor y a los juegos con el lenguaje, el narrador de Era el cielo también parece inclinarse hacia la producción de un incesante desajuste con respecto a las normas de lo establecido. Un diálogo transcurrido durante una reunión entre los guionistas de la tira diaria y el gerente de programación, hombre que hacía reír como nadie al narrador «con su humor rancio y su agudeza para captar y satisfacer la ansiedad del "público"» (Bizzio, 2011, p. 59), resulta un ejemplo paradigmático del modo en que el absurdo enrarece aquel clima de seriedad solemne del cual el narrador se burlaba en su descripción de los guionistas. El gerente de programación, fascinado con las enseñanzas de Osho, le ofrece con insistencia al narrador un libro del famoso líder espiritual para recibir como respuesta una serie de preguntas reiterativas que producen desconcierto y quiebran cualquier pretendida fluidez del intercambio comunicativo:

-Tomá, llevateló.

Era El libro del niño.

— ¿Acá es donde habla de los monos? —le pregunté sorprendido.

—Leelo y después hablamos.

— ¿Habla de televisión? -insistí.

-No, lo de la tele lo digo yo.

— ¿De quién es lo de la tele? —repetí (p. 59).

Era el cielo propicia un contacto entre la escritura literaria y la escritura televisiva, pero esto no implica que la novela se convierta en un guion de televisión, sino que, más bien, se vuelve el terreno de una disputa entre diferentes formas de trabajo y modos de vida. Frente a una industria de Lo Mismo que pretende convertir la extensión vital en tiempo racionalizado y productivo, la novela compone una temporalidad fracturada y eminentemente improductiva en términos de las exigencias del mercado, a través un recorrido errante por distintos episodios de la vida del narrador que pone en evidencia los fracasos antes que los éxitos, la experiencia extrañada del desajuste antes que la de la pertenencia. En «Art in the age of biopolitics», Boris Groys (2008) 
sostiene que ciertas prácticas artísticas contemporáneas como la documentación asumen como una de sus condiciones clave la politización creciente de lo viviente porque entienden que la vida, lejos de ser meramente un suceso natural, es una extensión temporal producida y diseñada artificialmente. En este sentido, Era el cielo subraya la artificialidad impostada de la temporalidad diseñada por el trabajo en la industria televisiva para inventar nuevos modos de narrar la extensión de una vida que disloquen toda idea de linealidad, «como si el tiempo hubiera enloquecido en alguna parte» (Bizzio, 2011, p. 179).

La novela narra, así, una vida escandida sin cesar por la desidentificación, por la vacilación inquietante de un sujeto que continuamente se desmarca de todas las instancias de pertenencia. ${ }^{5}$ En efecto, Diana y Julián, la mujer y el hijo del narrador, representan para él una fuente de seguridad y estabilidad, pero, lejos de toda plenitud, la relación con ellos no deja de estar recorrida por la sensación de un desajuste irreductible: «me asustó la idea de que todo fuera un error; no que fuera un error haber vuelto, sino que había sido un error irme de casa y que ese error continuaba ahora que había vuelto» (Bizzio, 2011, p. 160). Una vez más, las reflexiones de Groys alrededor de la temporalidad resultan pertinentes para iluminar algunos aspectos de la novela. En el ensayo «Camaradas del tiempo», el crítico analiza el time-based art a partir de su tematización de un «tiempo improductivo, perdido, sustraído de la Historia, excesivo» (2014, p. 90). Se trata de prácticas orientadas a capturar la imagen de un «"tiempo de vida" — un período irreductible a cualquier "sentido de la vida", a cualquier "logro vital", a cualquier relevancia histórica» (p. 91): un tiempo perdido, no teleológico que no conduce a ningún resultado ni meta, no se cristaliza en ningún producto definitivo y se sostiene indefinidamente en la modalidad del ensayo. Cuando la sensación de desencanto ante el tiempo por vivir, que se inscribe casi como premisa de la narración, resulta inevitable, ya que «el futuro se ha ido angostando hasta volverse invisible» (Bizzio, 2011, p. 14), Era el cielo compone el artificio de la temporalidad de una vida a través de una sucesión de episodios absurdos, de tropiezos, desvíos y fracasos que se alejan de cualquier fórmula racional del éxito y que no se encadenan de acuerdo a un orden de causalidad sino más bien según una contigüidad que resalta la arbitrariedad de la construcción.

Frente a los tiempos industrializados de la escritura para la televisión, la propia estructura de la novela da forma a una temporalidad improductiva e incierta ajena a toda linealidad y racionalización: «Al día siguiente, pero siete años atrás (la vida

5 Nuestra lectura difiere, en este punto, del análisis de la novela que propone Mariana Catalin. La crítica afirma que, en contraste con Realidad (la siguiente novela que publicaría Bizzio), Era el cielo propone un movimiento de territorialización, una «autorreflexividad sobre lo propio» que supone el riesgo de «la tranquilidad del encierro en lo ya conocido» (2014, p. 183). 
real es así), sostuve a Julián en mis manos» (p. 130). A través de los flashbacks, se delinea una experiencia de la memoria involuntaria que ya no habilita una forma de totalización de lo vivido, sino que más bien cobra consistencia alrededor de una materialidad impersonal del recuerdo: «me vino a la mente — cayó en mi mente, como una piedra, provocando un oleaje que bañó de terror las costas en miniatura de mi vida - la imagen de Julián entrando por primera vez al departamento» ( $\mathrm{p}$. 15; las cursivas son del original). Cuando se cruza por casualidad con uno de los hombres que violaron a su mujer y comienza a perseguirlo, el narrador sugiere una reflexión significativa: «Espiar a otro es enrarecerlo. Y cuanto más intrascendente es el registro de sus acciones, más raro resulta» (p. 157). Es posible hipotetizar que es precisamente este efecto de extrañamiento el que produce la misma novela a través del encadenamiento febril de una serie de episodios en apariencia banales, pero que cobran interés narrativo en la medida en que delinean la temporalidad de una vida signada por el fracaso, el desajuste y el humor como modalidades de la no pertenencia.

Si las prácticas de escritura de Vera y Diana están signadas, según el narrador, por la disciplina y el entusiasmo, y si además para Vera un buen día de trabajo culmina con una sensación de «productividad y satisfacción» (p. 68), el deseo de escribir del narrador figura como ajeno al orden de la actualización y a la lógica de la satisfacción, y se mantiene, en cambio, como pura potencia: «reconozco sin embargo un deseo sostenido a lo largo del tiempo: escribir; lo llamo deseo porque no escribo, o porque no escribí (o porque supone la posibilidad de escribir)» (p. 66). Este deseo articula y da cohesión al tiempo de vida, pero sosteniéndolo en una virtualidad abierta antes que en una forma acabada.

La figura del silencio que Barthes (2004) describe en Lo neutro como un juego no dogmático, no sistemático entre el hablar y el callar es entendida por Elena Donato (2012) bajo la forma de un «quizá sí, quizá no» que permite a su vez comprender el proyecto nunca actualizado del propio Barthes de escribir una novela. En la indefinición de este «quizá» se juega también la intensidad vital del narrador de Era el cielo. Antes que definirse por su adecuación a una forma reconocible de la vida social, parece sostenerse en la ambigüedad de la desidentificación y la no pertenencia: se gana la vida como guionista, pero no se identifica del todo con el modo de vida de sus colegas; desea escribir pero difiere indefinidamente la actualización de ese deseo.

Más allá del tiempo productivo del trabajo y de la estetización de los cuerpos dispuesta por la industria televisiva, Era el cielo explora otras posibilidades de configuración de la experiencia sensible que atienden a la heterogeneidad de lo imperceptible. La escena inicial de la novela exhibe el cuerpo no como sistema orgánico de formas y funciones, sino más bien como una composición variable de relaciones afectivas de velocidad y lentitud, de movimiento y reposo (Deleuze, 
2001): «sentí la misma combinación de vértigo y lentitud, de morosidad y agitación que sienten los que acaban de sufrir un accidente» (Bizzio, 2011, p. 9). Lo más impactante del episodio es el modo en que la narración construye un recorrido por la percepción que pone en primer plano una microscopía de la dinámica de los cuerpos y produce un extrañamiento sobre las lógicas cristalizadas que dominan la experiencia cotidiana: el «zigzagueo» (p. 10), los «mínimos cambios» (p. 10), la «lucha milimétrica» (p. 11), «la fuerza y la agilidad» de los cuerpos (p. 13). Otro procedimiento clave de este primer episodio - y muy recurrente en la narrativa de Bizzio - es la configuración de la experiencia perceptiva a través de la mediación e intervención de la técnica como modo de desnaturalizar la percepción y mostrarla como artificio: «moví la cabeza [...] como si la imagen fotográfica de ese primer vistazo hubiera estallado, ampliándose hasta volverse inabarcable» (p. 9).

Para un narrador que pierde confianza en su propia existencia y que, a lo largo de toda la novela, se ve expelido fuera de sí por fuerzas que lo exceden y sobre las que no ejerce ningún tipo de control, el plano material de las relaciones afectivas entre los cuerpos puede constituirse en una nueva modalidad de la experiencia. De este modo, la dinámica amorosa también se entiende a partir de una comunicación que transita en gran medida por la microscopía de los gestos y los movimientos imperceptibles de los cuerpos, más allá de la diferencia entre el sueño y la vigilia: «Reconozco una cierta coreografía del sueño en mis relaciones largas [...]. Me bastaba un leve roce de la punta de los dedos sobre su vientre para que ella girara hacia mí, no importaba cuán dormida estuviera. Me sentía» (p. 22; las cursivas son del original).

En El escritor comido las figuraciones de la no pertenencia se radicalizan a través de una mayor centralidad del cuerpo y una estética del despojamiento que intensifican los deslizamientos de la desidentificación que proliferaban en Era el cielo, ${ }^{6}$ al mismo tiempo que conducen hacia una exploración de las relaciones entre lo viviente, el trabajo de la escritura y las exigencias del mercado. Llevando hasta sus últimas consecuencias el deseo de Saupol de «vivirlo todo de nuevo otra vez, y otra, y una vez más, como un Fausto obsesivo» (Bizzio, 2010, p. 13), la novela ejecuta una sucesión de variaciones y transmutaciones alrededor de la corporalidad para narrar una vida que se hunde en el anonimato al alejarse de todos los marcos de inteligibilidad que la volvían reconocible. En línea con las operaciones que efectuaba Era el cielo sobre la temporalidad, El escritor comido despliega un campo de experiencia ajeno a la continuidad temporal que proporciona la conciencia de un sujeto, en el que la memoria aparece como una facultad interrumpida, extrañada: «“¿Qué literatura?”, le

6 En relación con esta cuestión, Marie Audran (2014) propone una lectura de El escritor comido a partir del dispositivo de la sustitución como procedimiento que afecta tanto a la identidad del escritor como a los géneros literarios (de la comedia de enredo a la novela indigenista, de la novela de aventuras al thriller). 
preguntó. "Punk” dijo Saupol. “¿Punk? ¿Literatura punk? ¿Qué es literatura punk?”, dijo ella. “¿Punk?”, preguntó Saupol. "Dijiste literatura punk”, dijo ella. "¿Yo dije literatura punk?", dijo Saupol llevándose un dedo al pecho» (p. 39-40).

La experiencia extrañada que prolifera más allá de las retóricas de la pertenencia y el reconocimiento, una vez que Saupol abandona su vida como escritor exitoso, emerge como posibilidad de explorar nuevas configuraciones de lo sensible y de las relaciones de afectividad entre los cuerpos, pero también se convierte en una experiencia fácilmente apropiable por una lógica mercantil que valoriza crecientemente la contingencia y la variabilidad, las redes «flexibles, mutantes, en permanente recomposición» (Ingrassia, 2013, p. 8). Como sugiere Laera en su lectura de la novela, Mauro Saupol encarna «tanto la posible desfiguración del artista como su reconversión en un bien cotizable en el mercado» (2014, s. p.). Las transformaciones del cuerpo de Saupol son leídas por Laera en serie con una contemporaneidad en que la estética, como señala Groys, interviene ante todo en la producción de un yo público. En el ensayo «La obligación del diseño de sí», Groys refiere precisamente a la exigencia omnipresente en la sociedad contemporánea de que cada ciudadano asuma la «responsabilidad ética, estética y política por el diseño de sí» (2014, p. 32). El diseño como estetización de la vida supone un posicionamiento tanto ético como político porque, a través del diseño de sí y del entorno, «uno declara de alguna manera su fe en ciertos valores, actitudes, programas e ideologías. De acuerdo con este credo, uno es juzgado por la sociedad» (p. 33).

En este sentido, El escritor comido lleva al extremo el imperativo contemporáneo del diseño al narrar sucesivas intervenciones sobre el cuerpo de Saupol que lo vuelven irreconocible incluso para sí mismo. Mientras que las pacientes de los cirujanos se paseaban en la fiesta a la que asiste el narrador de Era el cielo «como ejemplos de pericia y precisión», como modelos de «la forma adecuada, la función aceptable» (Bizzio, 2011, p. 42), la transfiguración del cuerpo mediante la cirugía estética conduce a Saupol en El escritor comido hacia el completo extrañamiento: «Había sido varios durante el proceso: la cara cambiaba a medida que el nuevo tejido era aceptado [...]. Finalmente, [...] sus rasgos dejaron de variar y se estacionaron en los de un extraño total» (Bizzio, 2010, p. 142). Cuando el cuerpo deja de reconocerse como propio, la identidad tampoco puede permanecer como un sustrato estable.

En Era el cielo, el narrador se conmovía ante la desolación enigmática de una frase de Peter Handke que expresaba una necesidad de que la vida propia sea narrada por otro: «Cuéntame una historia de mí; quizá no sea correcta, pero cuéntame de mí. Necesito una versión de mí» (Bizzio, 2011, p. 75). Todavía más radical, Saupol se sustrae al imperativo del autodiseño para dejar la narración de su vida en manos de Gil y sumergirse, por última vez, en la ausencia de sí, en una vida anónima e irreconocible: «ya no puedo responder a nada. [...] Me voy esta misma tarde. 
Quiero empezar una nueva vida. Yo ya no soy Mauro Saupol. Ni siquiera soy un escritor» (Bizzio, 2010, p. 178). En El escritor comido emerge con mayor fuerza la impersonalidad de una experiencia ajena a la racionalidad y a la conciencia, así como desligada del paradigma del signo. La configuración de una vida radicalmente heterogénea e inestable, dislocada de toda forma de pertenencia puede rastrearse especialmente en la narración del paisaje que ofrece la novela: «No había dos metros que fuesen iguales. La jungla, sirviéndose de muy pocos elementos —árboles, agua, barro, arena-, barajaba un millón de formas distintas, siempre nuevas, únicas y cambiantes, imposibles de recordar» (p. 93).

Si la potencia política de las prácticas estéticas analizadas por Garramuño en La experiencia opaca se hallaba en el «abandono de un paradigma de la resistencia concebido, como lo era en la época, como oposición reivindicatoria ante un sistema constituido» (2009, p. 85), la apuesta de estas novelas de Bizzio no radica tampoco en defender la autonomía de lo literario frente a la fuerza omnívora del mercado, sino ante todo en la puesta en discusión de las relaciones entre las prácticas de escritura, el trabajo y la vida. Era el cielo y El escritor comido reconocen que el capital en tanto dispositivo de gobierno produce formas de vida y diseña subjetividades a través de la configuración de una estética de los cuerpos vinculada a un cierto orden de los discursos, los espacios y los tiempos. Entre el trabajo y la vida, entre el deseo y el mercado, los límites y criterios del régimen contemporáneo de producción literaria se vuelven porosos y fluctuantes. En el marco de estas condiciones, las novelas interrogan la imbricación entre la vida y la escritura para discutir las formas de trabajo del escritor, al mismo tiempo que exploran posibilidades de vida, desfiguraciones de los cuerpos y temporalidades improductivas que ponen en suspenso, al menos provisoriamente, la subsunción total de la vida al capital.

\section{Referencias bibliográficas}

1. Agamben, G. (2004). Estado de excepción. Homo sacer II, I. Buenos Aires: Adriana Hidalgo.

2. Arendt, H. (1993). La condición humana. Barcelona: Paidós.

3. Audran, M. (2014). Escritores, monstruo y supervivencia (César Aira, Daniel Guebel, Sergio Bizzio). Amerika. Mémoires, identités, territoires, 11. Recuperado de http://amerika.revues.org/5310

4. Barthes, R. (2004). Lo neutro. Curso del Collège de France, 1978. México: Siglo Veintiuno.

5. Barthes, R. (2005). La preparación de la novela. Notas de cursos y seminarios en el Collège de France: 1978-1979 y 1979-1980. Buenos Aires: Siglo Veintiuno.

6. Berg, E. H. (1996). La joven narrativa argentina de los '90': ¿nueva o novedad? Revista Letras, 45, 31-40.

7. Bizzio, S. (2010). El escritor comido. Buenos Aires: Mansalva.

8. Bizzio, S. (2011). Era el cielo. Buenos Aires: Interzona. 
9. Bizzio, S. (2012). Chicos. Buenos Aires: Interzona.

10. Catalin, M. (2014). Con los ojos bien abiertos. Bizzio, Chejfec, Babel. Rosario: Fiesta E-diciones, CELA.

11. Deleuze, G. (1996). Post-scriptum sobre las sociedades de control. En Conversaciones. 1972-1990 (pp. 277-286). Valencia: Pre-Textos.

12. Deleuze, G. (2001). Spinoza: filosofía práctica. Barcelona: Tusquets.

13. Donato, E. (2012). Sólo se logra escribir sobre lo que se ama. El escritor y lo imaginario en Roland Barthes. Exlibris, 1(1), 122-143.

14. Féral, J. (2002). Theatricality: the specificity of theatrical language. SubStance, 31(2/3), 94-108.

15. Foucault, M. (2006). Seguridad, territorio, población. Curso en el Collège de France (1977-1978). Buenos Aires: Fondo de Cultura Económica.

16. Foucault, M. (2008). Nacimiento de la biopolítica. Curso en el Collège de France (1978-1979). Buenos Aires: Fondo de Cultura Económica.

17. Garramuño, F. (2009). La experiencia opaca. Literatura y desencanto. Buenos Aires: Fondo de Cultura Económica.

18. Garramuño, F. (2015). Mundos en común. Ensayos sobre la inespecificidad en el arte. Buenos Aires: Fondo de Cultura Económica.

19. Groys, B. (2008). Art in the age of biopolitics. From artwork to art documentation. En Art power (pp. 53-65). Cambridge: MIT Press.

20. Groys, B. (2014). Volverse público. Las transformaciones del arte en el ágora contemporánea. Buenos Aires: Caja Negra.

21. Ingrassia, F. (Comp.). (2013). Estéticas de la dispersión. Rosario: Beatriz Viterbo.

22. Krauss, R. (1979). Sculpture in the expanded field. October, 8, 30-44.

23. Krauss, R. (1999). Reinventing the medium. Critical Inquiry, 25(2), 289-305.

24. Laddaga, R. (2006). Estética de la emergencia. La formación de otra cultura de las artes. Buenos Aires: Adriana Hidalgo.

25. Laddaga, R. (2007). Espectáculos de realidad. Ensayo sobre la narrativa latinoamericana de las últimas dos décadas. Rosario: Beatriz Viterbo.

26. Laera, A. (2014). Exhibición de los cuerpos, ¿cotización del escritor? Sala Grumo. Recuperado de https://docs.wixstatic.com/ugd/de3363_a943409e22e84806b6cfb77 adf837967.pdf

27. Laera, A. (2016). Más allá del dinero: ficciones del trabajo en la Argentina contemporánea y la fetichización del escritor. Badebec, 6 (11), 158-173.

28. Lazzarato, M. (2013). La fábrica del hombre endeudado. Ensayo sobre la condición neoliberal. Buenos Aires: Amorrortu.

29. Ludmer, J. (2010). Aqui América Latina. Una especulación. Buenos Aires: Eterna Cadencia.

30. Oubiña, D. (2010). El silencio y sus bordes. Modos de lo extremo en la literatura y el cine. Buenos Aires: Fondo de Cultura Económica.

31. Onfray, M. (2009). Cinismos. Retrato de los filósofos llamados perros. Buenos Aires: Paidós.

32. Silverman, K. (2009). Photography by other means. En Flesh of my flesh. Stanford: Stanford University Press.

33. Virno, P. (2008). Gramática de la multitud. Para un análisis de las formas de vida contemporáneas. Buenos Aires: Colihue. 